
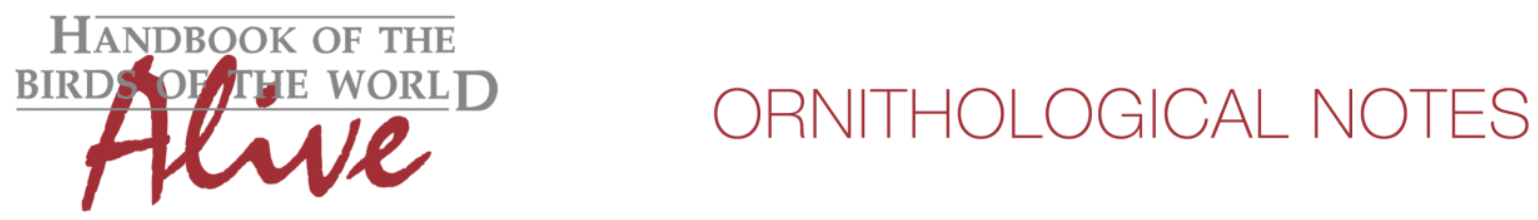

\title{
Notes on the vocalizations of Marsh Wren (Cistothorus palustris)
}

Peter Boesman

In the following we briefly analyze and compare voice of the different races of Marsh Wren (Cistothorus palustris). We also try to quantify the extent of any vocal differences using the criteria proposed by Tobias et al. (2010), as a support for taxonomic review.

We have made use of sound recordings available on-line from Xeno Canto (XC).

Our main interest is to compare the 'Western group' (paludicola, browningi, pulverius, plesius, aestuarinus, clarkae and deserticola) with the 'Eastern group' (remaining NorthAmerican races), and the disjunct Mexican race tolucensis as a third group.

Some examples of song:

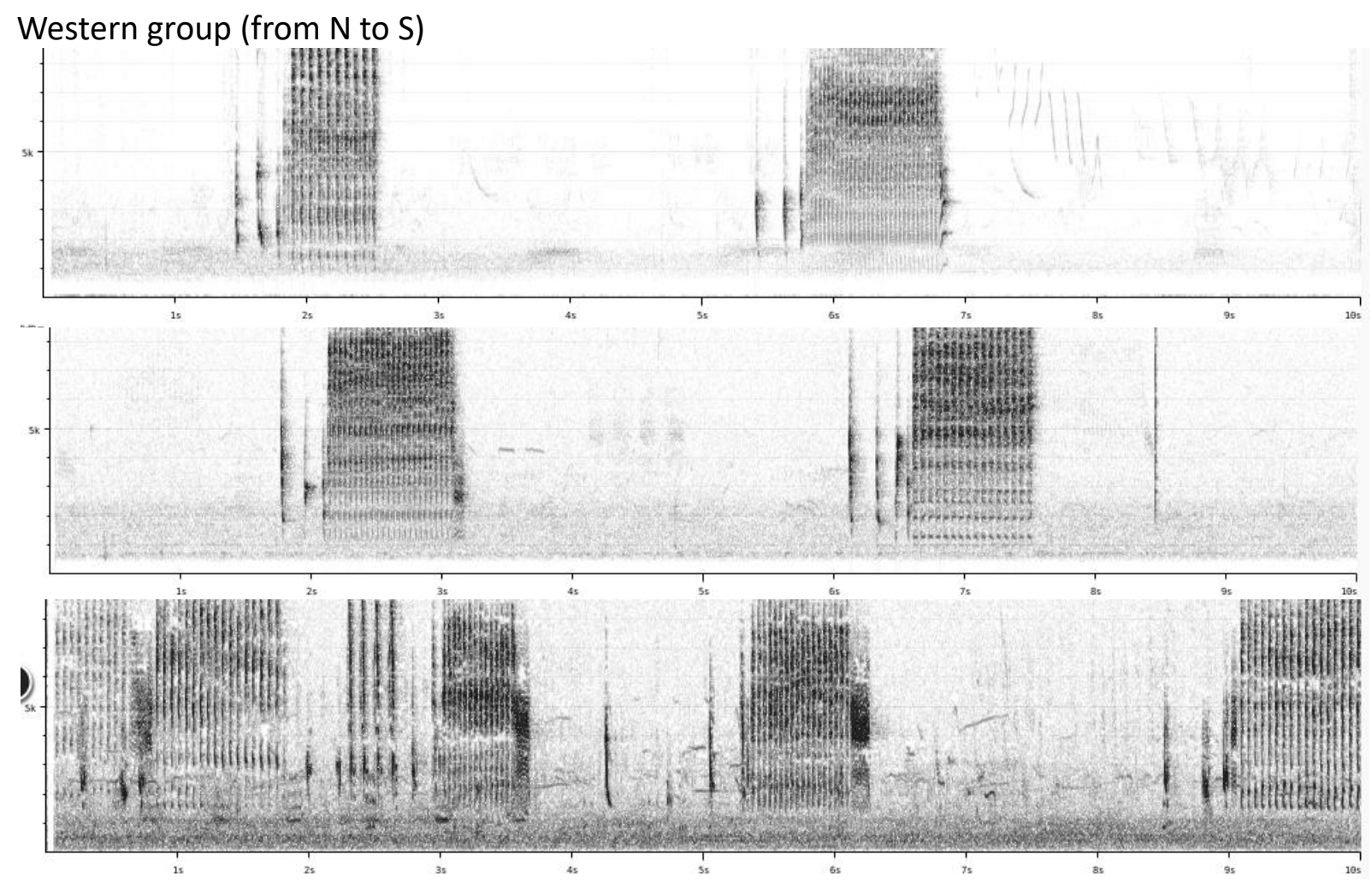

Eastern group (from $\mathrm{N}$ to $\mathrm{S}$ )

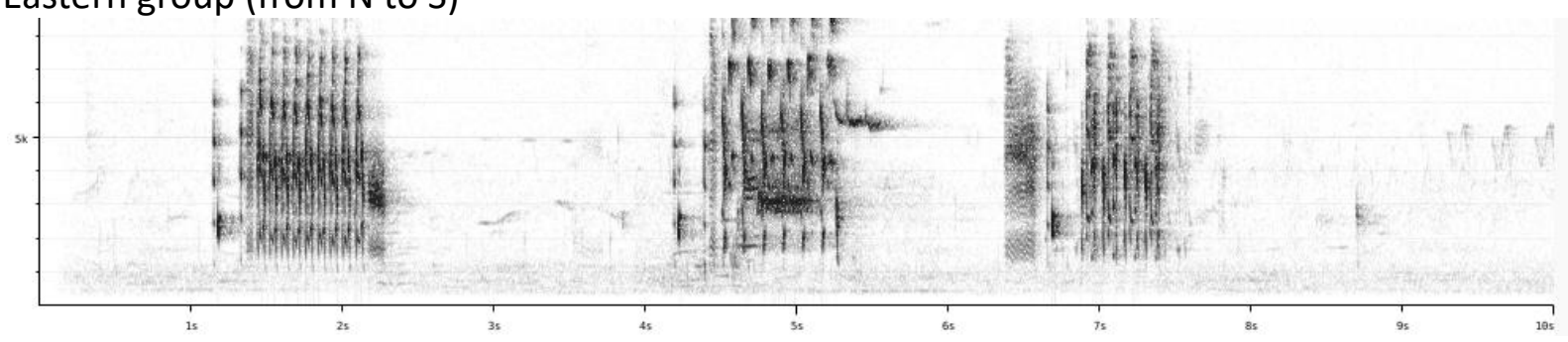




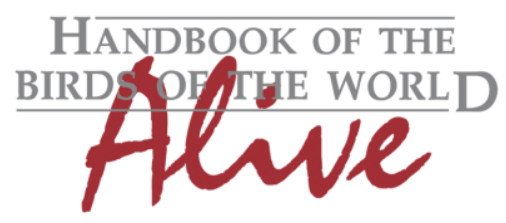

\section{ORNITHOLOGICAL NOTES}
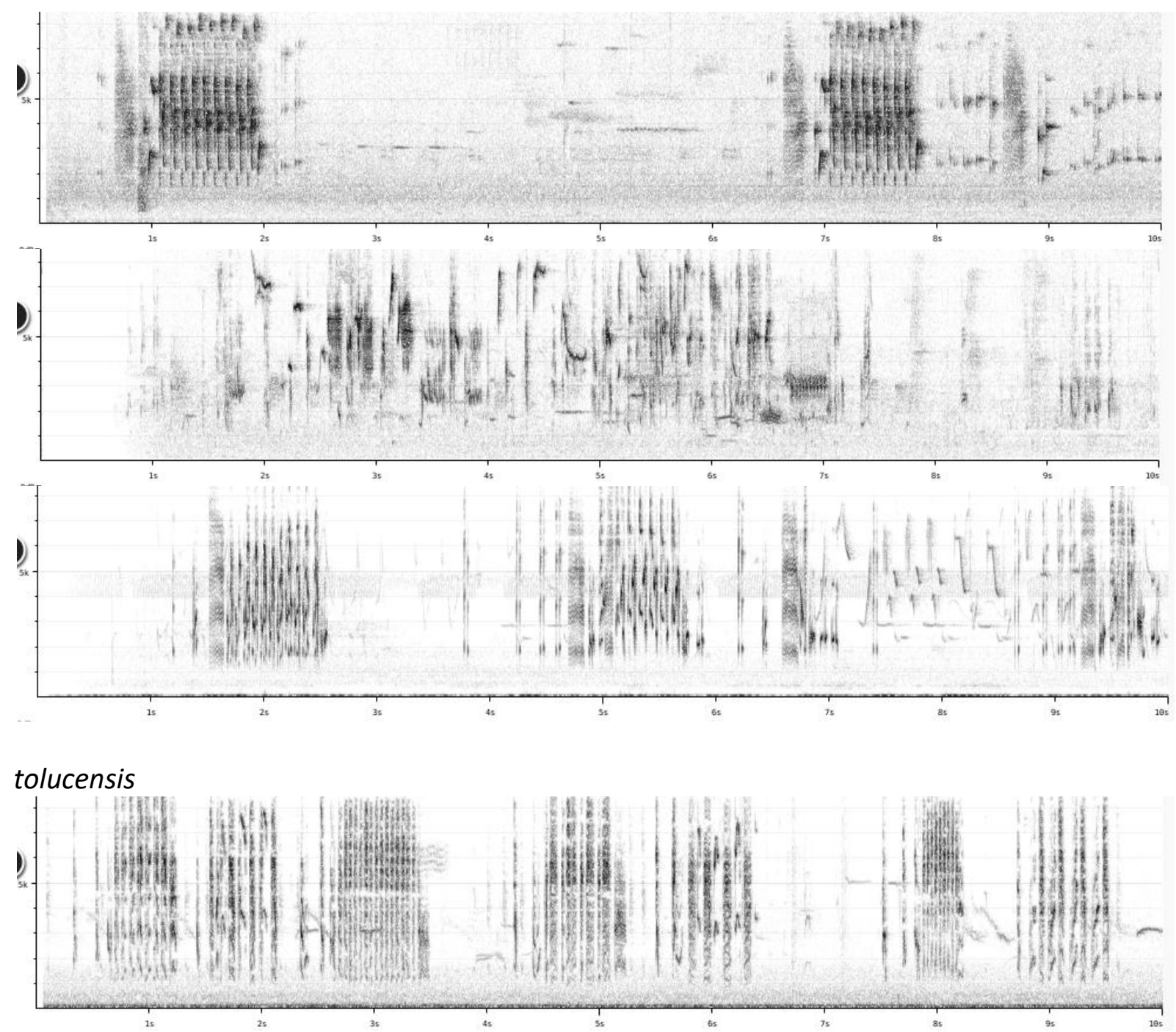

It is clear from the above examples that there is quite some variability in song, and vocal differences between the three groups are not at all obvious. Application of the Tobias criteria would lead to rather small scores, as vocal differences are seemingly more subtle than can be expressed by the basic sound parameters (phrase length, note duration, $\mathrm{min} / \mathrm{max}$ frequency etc.).

This may come somewhat as a surprise, given that voice of Marsh Wren has been the topic of several in depth studies, which concluded there were major vocal differences between the Western and Eastern group .

Kroodsma (2005) summarizes several decades of study work, and indicates what he considers the main vocal differences:

- On a holistic level, Western birds have a repertoire consisting of a larger quantity of different phrases (c. 100) compared to Eastern birds (c. 30-60)

- On a holistic level, Western birds typically follow a sequence of all different phrases

(ABCDEFG...) while Eastern birds sing a more alternating series of phrases (ABABABCBCD...)

- On a detailed level, the trilled part, when looking on a detailed time scale is different: in 


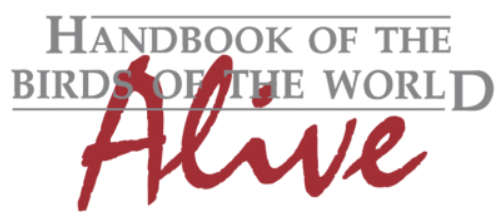

\section{ORNITHOLOGICAL NOTES}

Eastern birds, each element of the trilled part has some three notes with fundamental frequency around $2 \mathrm{kHz}$, and clear harmonics. In Western birds, each element of the trilled part is either a noisy harsh note or some type of whistle.

It would lead us too far to check whether we could come to similar conclusions by examining the available on-line recordings (and the length of the available recordings would certainly not allow to confirm the first statement). The last feature however is easily verified, for which we have selected randomly a recording from Quebec (Eastern bird, XC256293): strophe 1

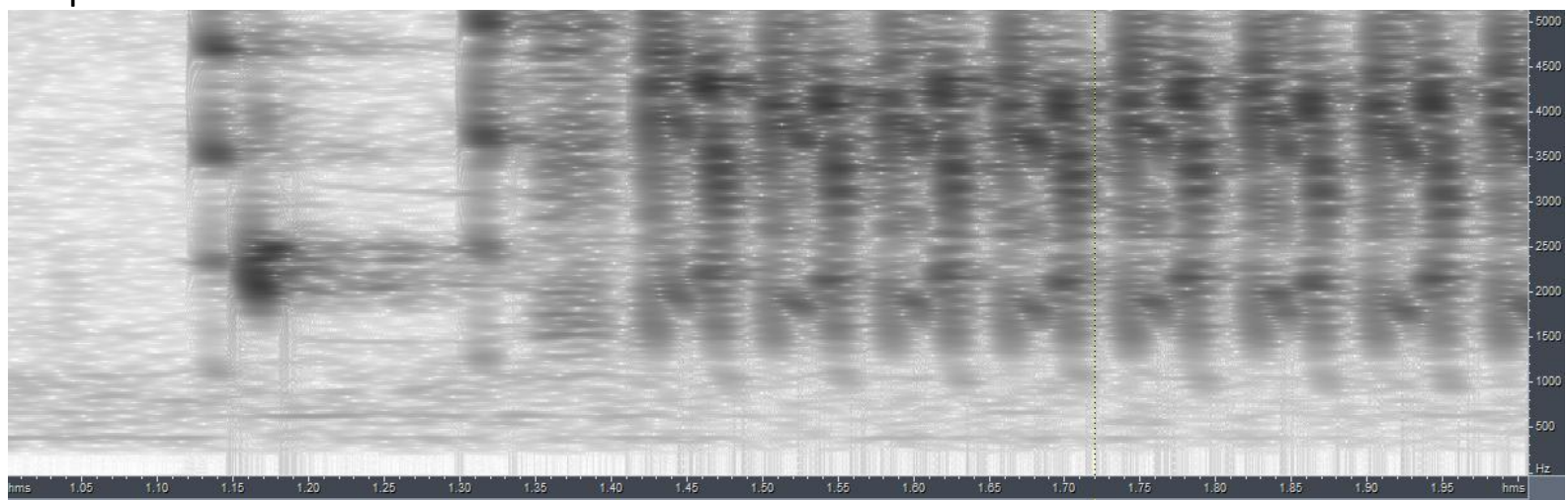

strophe 2

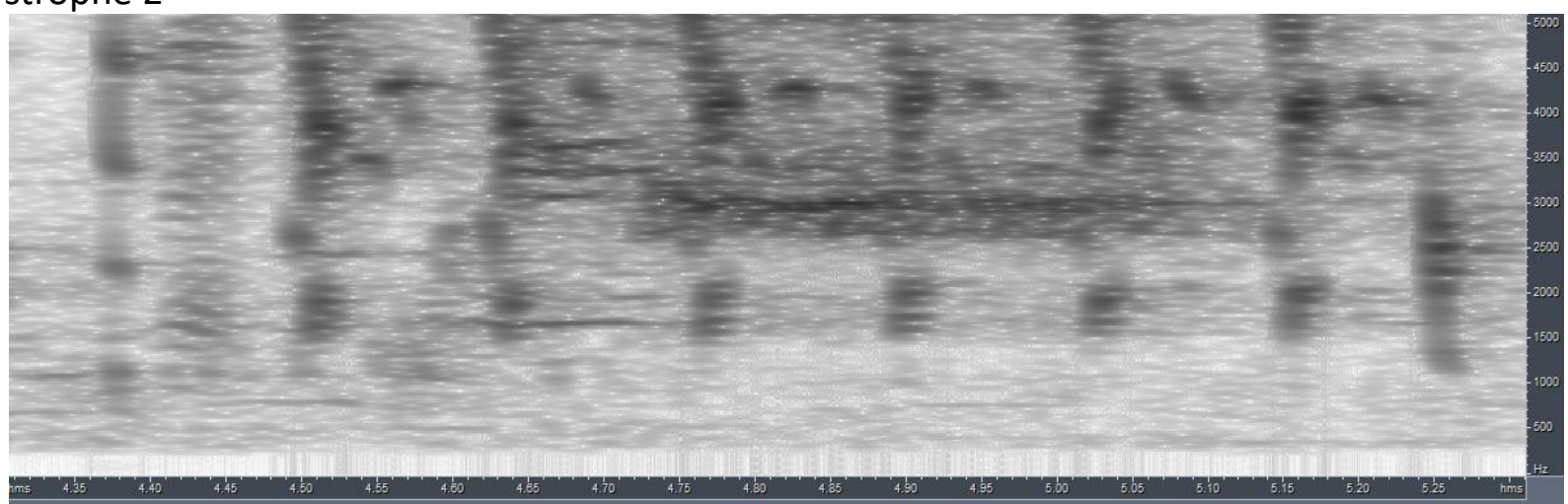

strophe 3

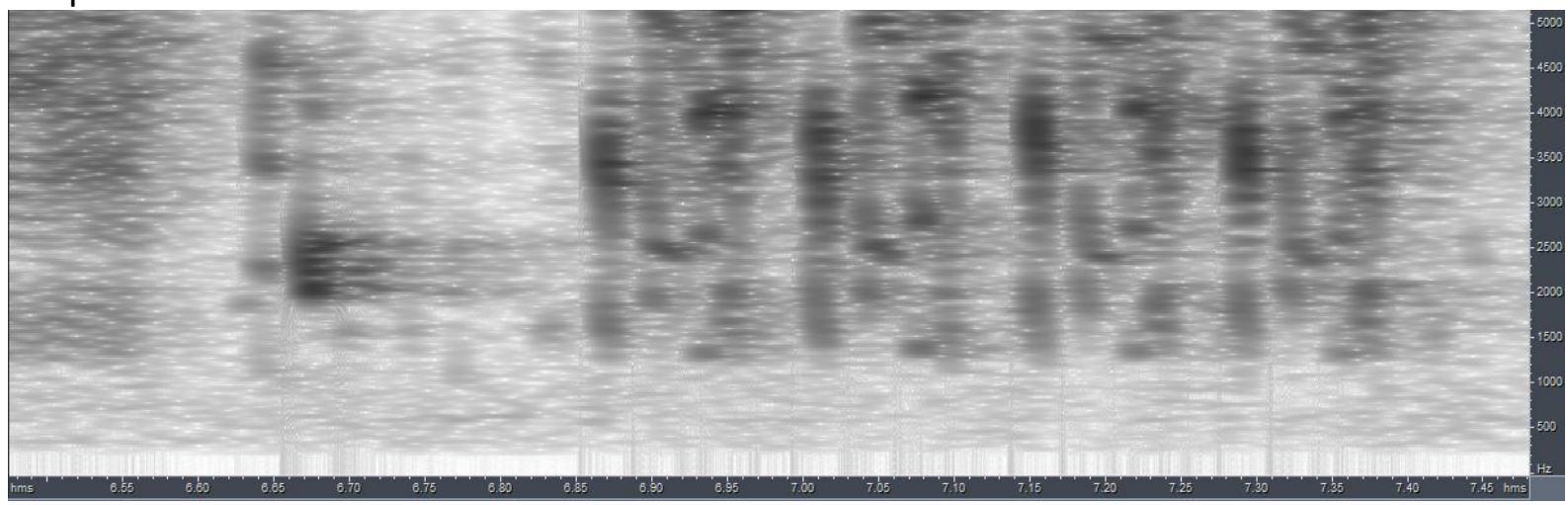

etc.

to be compared with a typical Western recording (California, XC178010): 


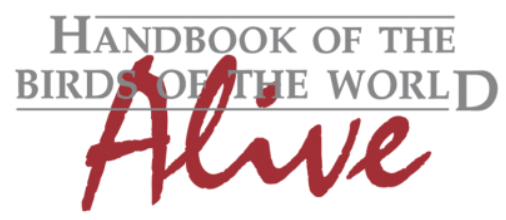

\section{ORNITHOLOGICAL NOTES}

strophe 1

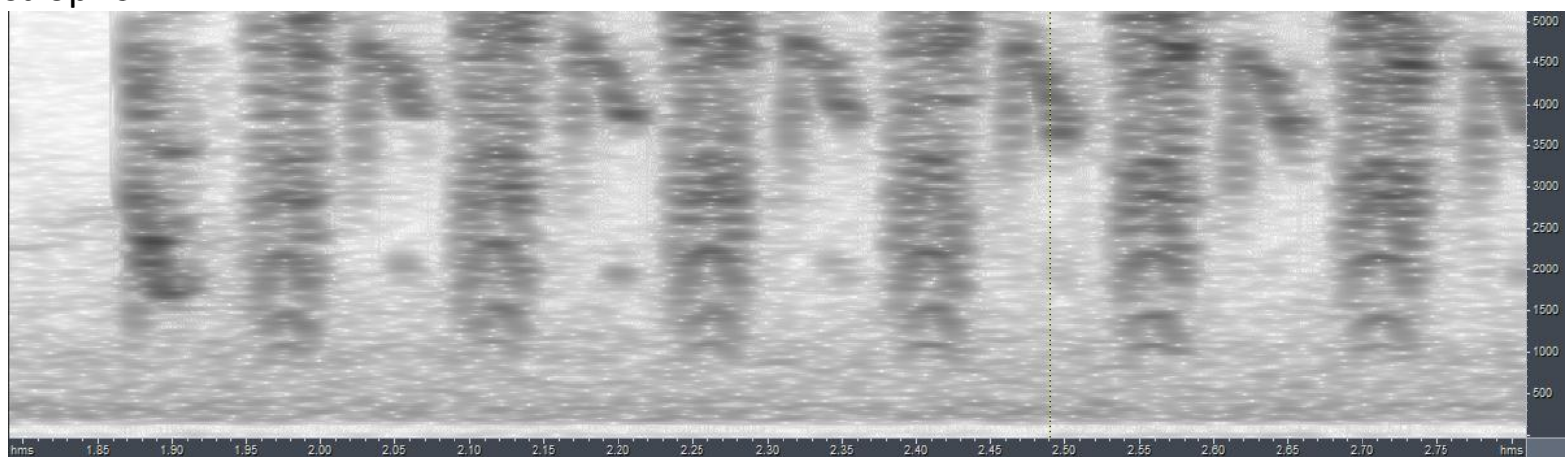

strophe 2

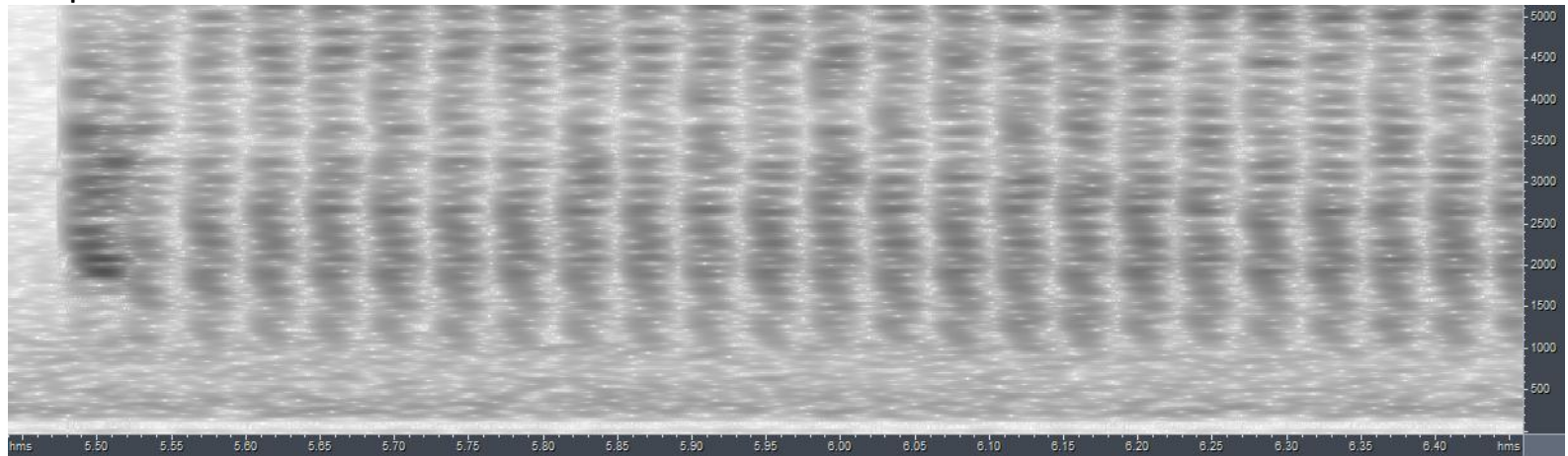

strophe 3

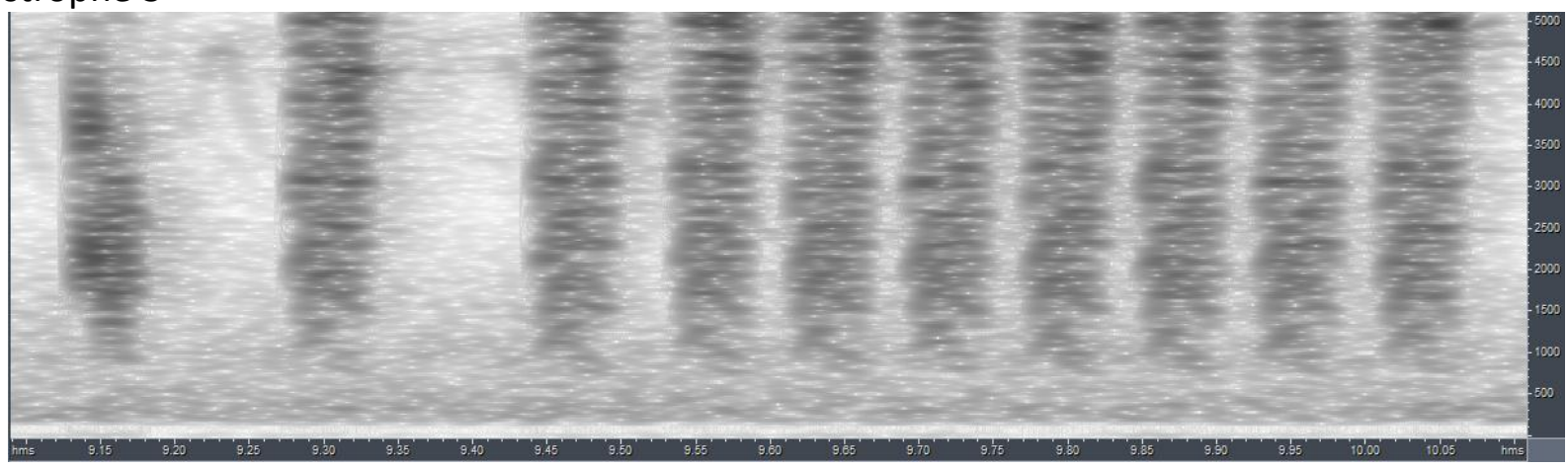

strophe 4

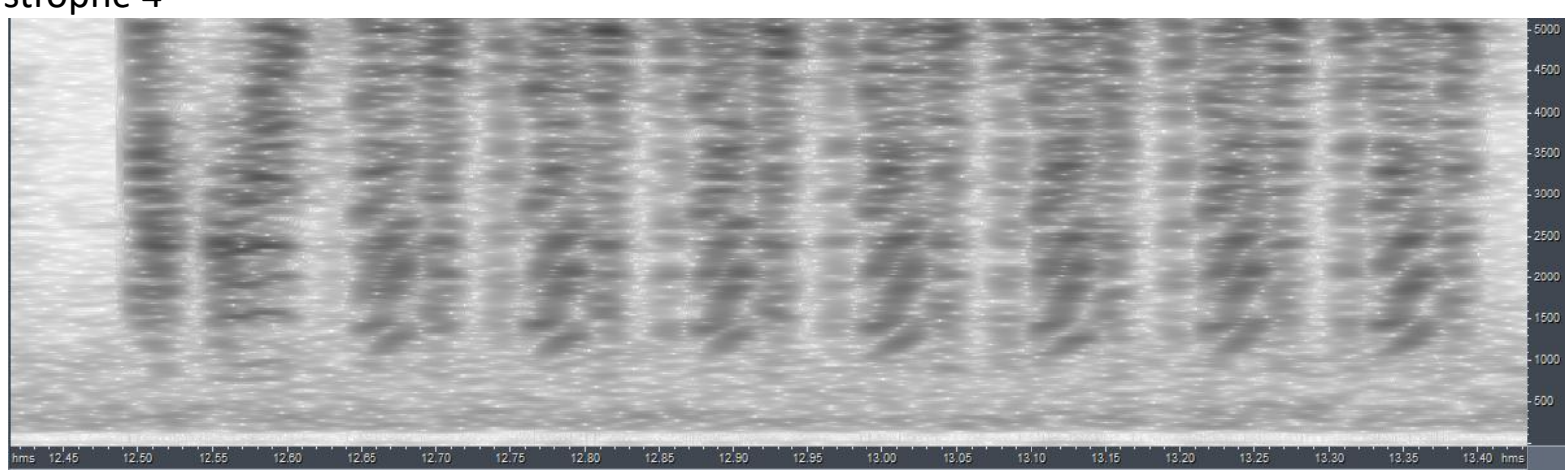

This seems to confirm that elements in trills of Eastern birds have notes around $2 \mathrm{KHz}$ with 'normal harmonics', while elements in Western birds have many frequency bands suggesting rather polyphonic songs. 


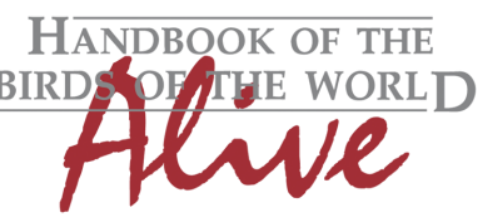

\section{ORNITHOLOGICAL NOTES}

A logical question then is where race tolucensis stands. Analysis of XC290130:

strophe 1

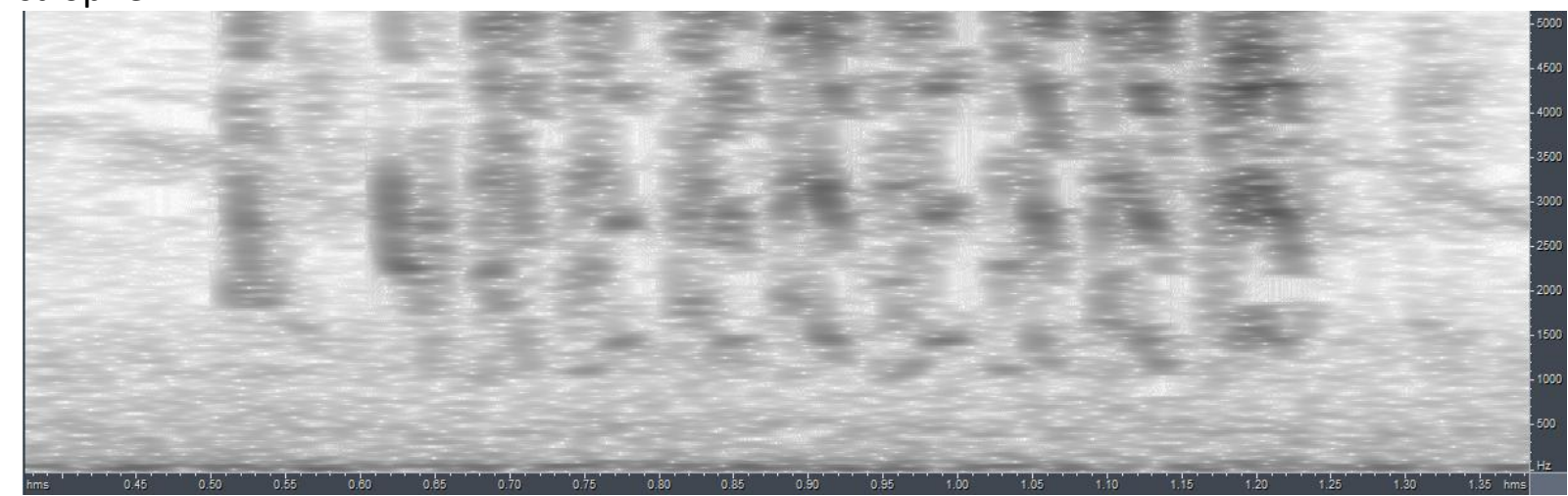

strophe 2

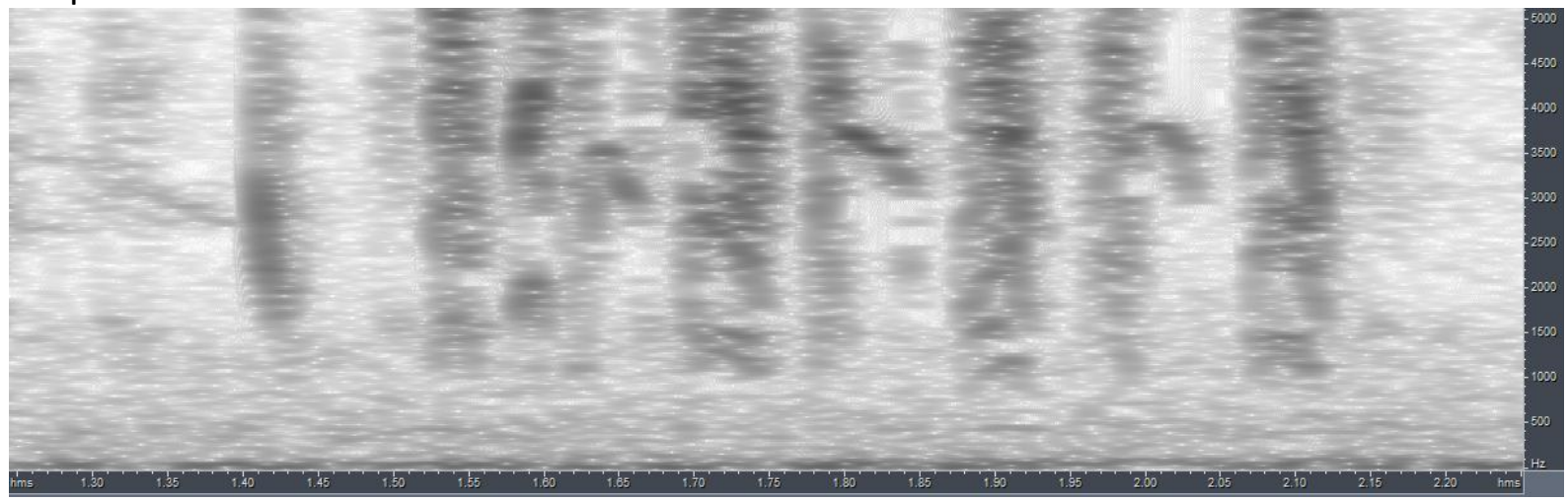

strophe 3

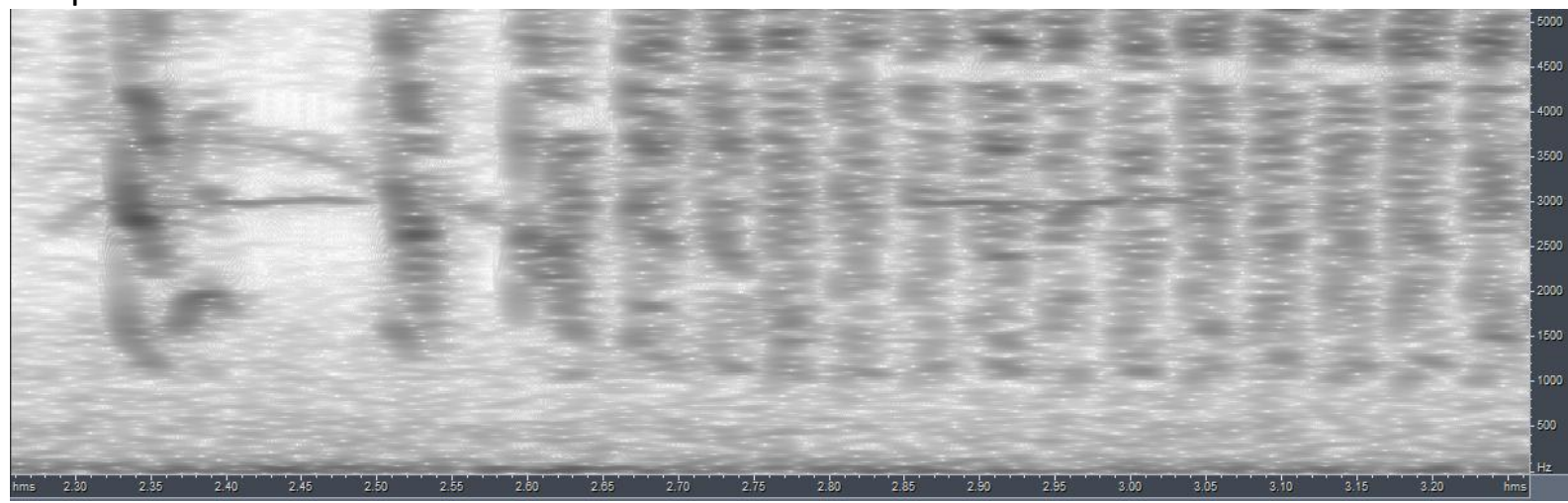

strophe 4

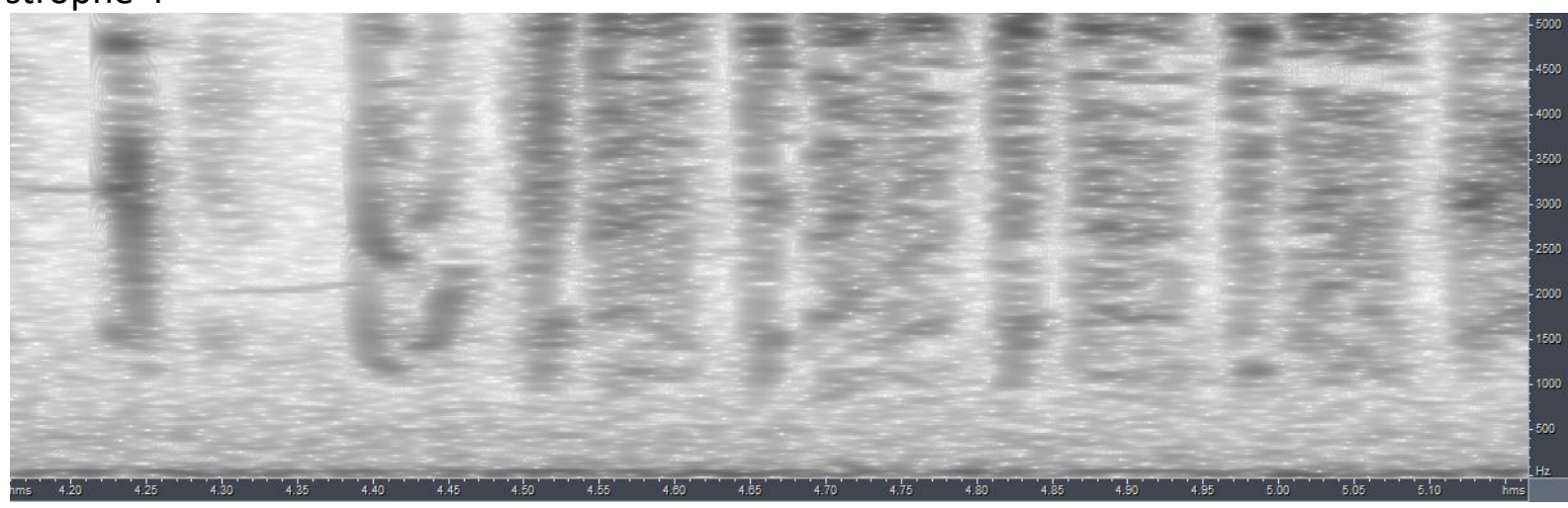

It would seem that at least strophe 2-4 are rather of the Western type. 

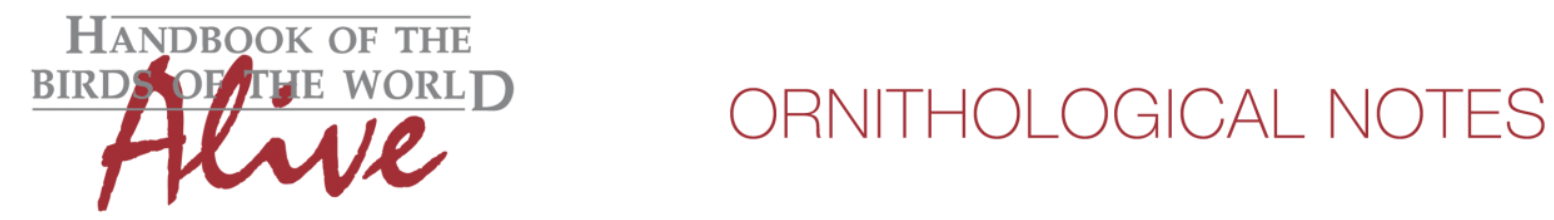

Pieplow (2010) (see http://earbirding.com/blog/archives/1897) focussed more on the introductory notes preceding the trilled phrases: The introductory notes of Western birds almost always consist of two quick, low, noisy "tuk" sounds. The second "tuk" usually runs right up against the start of the trill: "tuk tukRRRRRRRRRR." Eastern birds, by contrast, very often start with a single nasal and/or buzzy note, which might be transliterated as "beer" or "bzt."

When looking at our initial sonograms at the start of this note, this seems to be indeed another distinctive feature (on average), with apparently tolucensis again rather of the Western type.

All in all, we can conclude that vocal differences between the Eastern and Western group are not obvious, but when looking at a holistic level (total song phrase repertoire per male) and on a detailed level (frequency properties of a single element in every trill) there are clear differences.

These vocal differences do not score high when applying Tobias criteria, because the basic sound parameters are not in clearly different ranges. We need to apply the same standards for quantifying vocal differences as in other cases, and as such the difference in note shape of basic elements in the trill (1-2) and the larger vocal repertoire (1-2) lead to a total vocal score of about 3 .

This being said, it is clear from the study work explained by Kroodsma that the complexity of the vocal repertoire seems to play a role in reproductive isolation. On one hand, this reemphasizes the importance of voice as a possible barrier for gene flow, even in the case of an oscine passerine where the vocal differences at first sight are far from obvious to the human ear, and on the other hand it illustrates the limits of the Tobias system, which predicted from the very start that in some cases $(<5 \%)$ the treshold score of 7 would not necessarily be reached when scoring good species pairs.

This leaves us with a difficult case, in which only an integrative approach, preferably combined with field tests checking reproductive isolation, will allow us to prove Eastern and Western birds are indeed two good species.

This note was finalized on 15th April 2016, using sound recordings available on-line at that moment. We would like to thank in particular the many sound recordists who placed their recordings for this species on XC.

\section{References}

Kroodsma D. (2005). The Singing Life of Birds. Houghton Mifflin Company. Boston, New York. 


\section{Recommended citation}

Boesman, P. (2016). Notes on the vocalizations of Marsh Wren (Cistothorus palustris). HBW Alive Ornithological Note 286. In: Handbook of the Birds of the World Alive. Lynx Edicions, Barcelona. (retrieved from http://www.hbw.com/node/1251728 on 12 October 2016). 